(C) 1982. The Genetical Society of Great Britain

\title{
A DISTINCT CLASS OF PEAS (PISUM SATIVUM L.) FROM AFGHANISTAN THAT SHOW STRAIN SPECIFICITY FOR SYMBIOTIC RHIZOBIUM
}

\author{
J. P. W. YOUNG and P. MATTHEWS \\ John Innes Institute, Colney Lane, Norwich NR4 7UH, U.K.
}

Received 20.x.81

\section{SUMMARY}

\begin{abstract}
A phenetic analysis showed that peas from Afghanistan which are resistant to nodulation by European strains of Rhizobium leguminosarum form a close-knit group. They are quite distinct from susceptible lines found in Afghanistan, which are much more diverse and show a range of variation almost as extensive as a world-wide sample. The resistant peas possess a number of distinctive features, including small flowers, small pods and brown-marbled seeds. A high proportion are also resistant to powdery mildew (Erysiphe polygoni). They were collected over a wide area of Afghanistan, and a Rhizobium-resistant line from Israel is also very similar. Limited evidence suggests that resistant and susceptible varieties may coexist throughout the area from Israel to Afghanistan, and that "universal" Rhizobium strains, able to nodulate resistant plants, may have a similar range. However, both resistance and universal strains were left behind when pea cultivation spread north into Europe.
\end{abstract}

\section{INTRODUCTION}

THE peas of Afghanistan are rich in genetic diversity (Govorov, 1928). One characteristic of certain forms that has attracted considerable attention is their resistance to European strains of the root-nodule symbiont, Rhizobium leguminosarum. This was observed by Govorov (1937) who speculated that "aboriginal races" of bacterium from Afghanistan might be needed to nodulate these plants. The resistance was rediscovered by Lie (1971), who later found strains of Rhizobium for Turkey, Israel, and Afghanistan which were able to nodulate resistant plants as well as European peas (Lie, 1978). On the basis of the available evidence, we can thus recognise two classes of peas and two classes of $R$. leguminosarum (Lie, 1978; Young et al., 1982). Some strains of Rhizobium from Afghanistan, Israel and Turkey appear to be universal, in that they will nodulate all varieties of Pisum sativum with which they have been tested, while European strains are limited in host range. Most peas are susceptible to nodulation by these limited strains, but some varieties from Afghanistan, Israel, Turkey and Iran are partially or completely resistant. In this paper, Rhizobium-resistance and susceptibility refer to nodulation by European strains.

A recent extensive survey of the John Innes pea collection failed to find any genotypes resistant to a universal strain of $R$. leguminosarum, but identified a number of lines, mostly from Afghanistan, resistant to limited strains (Young et al., 1982). There is an extensive computer data bank of origin and phenotypic information about lines in the John Innes Pisum Germplasm Collection, and these data have been used to answer a number of questions: is resistance associated with any other phenotypic 
characteristics amongst Afghan peas; are resistant peas distinctive when compared with world-wide material, and what is the geographic distribution of resistance?

\section{METHODS}

\section{(i) Origin of the pea lines used}

Of the 375 lines screened for nodulation variants by Young et al. (1982), suitable computer records existed for 172 , which were used in the present study. These included all the lines from Afghanistan, some Western cultivars, and primitive lines from many countries in Asia and Africa. Also included was "cv. Afghanistan" (JI 1357), a line known to be resistant to European Rhizobium (Lie, 1971, 1978). Most lines in the Collection were obtained from other collections, and documentation of origins is incomplete, but the available information is summarized in table 1 for the 41 Afghan lines and the two other known resistant lines.

\section{(ii) The data base}

Computer-based records of the John Innes Pisum Germplasm Collection have been in use for some time (Johnson, Snoad and Davies, 1971), but a completely new system has recently been established on a DEC PDP 11/60 machine (Matthews and Rushbrook, 1981). There are some 1400 lines in the collection and more than 50 characteristics are recorded for each line. The information on each line is stored as a single 256-byte record in a direct access file, which is accessible to a number of input and retrieval programmes. Some other information, principally on disease resistance, is available for some lines, and this is stored in the same file.

\section{(iii) Calculation of phenetic distances}

All available information was used to calculate phenetic distances between lines. A few characters had to be omitted because their recording was incomplete, each of the remaining 49 characters was recorded for at least 95 per cent of the lines used. All characters had discrete states, those that had only one or two states were used directly. Each ordered multistate character was recoded into two or more binary characters (e.g., "small, medium, or large" recoded as " 00,10 or 11 "). Unordered multistate characters (e.g., colour) were recoded in accordance with their known genetic basis: one character per genetic locus. After this recoding there were 70 characters. distance

The distance between two lines was computed as the average Euclidean

$$
d=\left[\frac{1}{n} \sum_{i=1}^{n} D_{i}^{2}\right]^{1 / 2}
$$

where $D_{i}$, the difference for character $i$, is zero for a match and unity for a mismatch, and $n$ is the number of characters (excluding any missing data). Thus there was no standardization, differences at all characters being weighted equally, in accordance with the recommendations of Sneath and Sokal (1973). 
TABLE 1

Origin of lines from Afghanistan and other Rhizobium-resistant lines

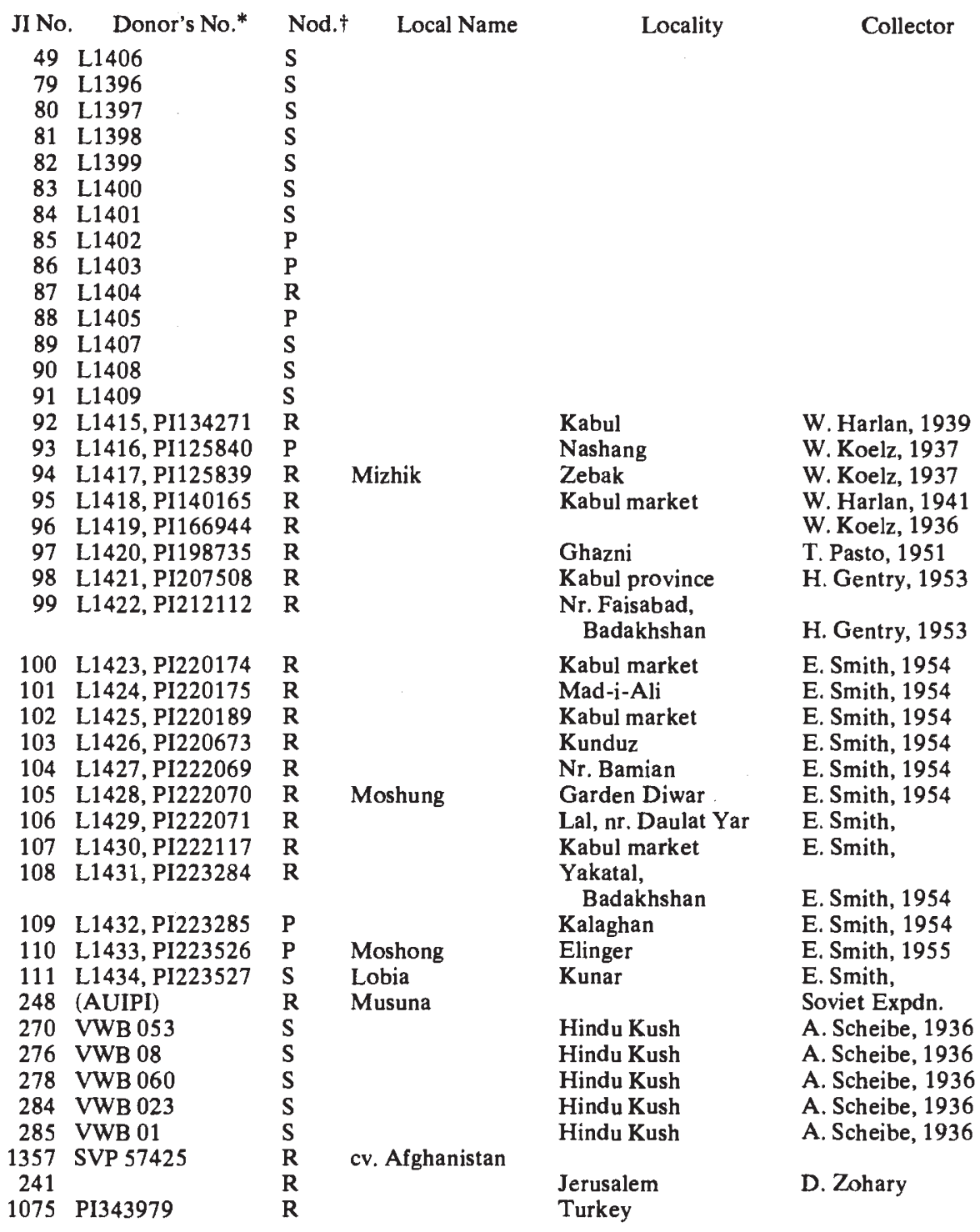

* Donor collections: $\mathbf{L}=$ Weibullsholm, Sweden; $\mathrm{PI}=$ U.S. Plant Introduction Service; $A$ UIPI = All Union Institute of Plant Industry, Leningrad, U.S.S.R.; VWB = Van Waveren \& De Bres Gmbh, Gottingen, W. Germany; SVP = Stichting voor Plantenveredeling, Wageningen, Holland.

$\dagger$ Nodulation by European strains of $R$. leguminosarum: $\mathrm{S}=$ susceptible; $\mathrm{R}=$ resistant; $\mathrm{P}=$ partially resistant (data from Young et al., 1982). 


\section{Results}

(i) Phenetic relationships among Afghan lines

Phenetic distances amongst the 31 Afghan lines, with the two nonAfghan resistant lines included for comparison, are shown in table 2, in which the lines have been reordered to bring similar lines together. No

\section{TABLE 2}

Phenetic distance matrix for pea lines from Afghanistan. All possible pairwise distances are shown, the lines appearing in the columns in the same order as in the rows. Distances, $\mathrm{d}$, are coded as single digits: 0 is $\mathrm{d}<0.05 ; 1$ is $0.05 \leq \mathrm{d}<0.1$; and so on up to 9, which is $0.45 \geqq \mathrm{~d}<0.5$. Blanks indicate $\mathrm{d} \leqq 0.5$

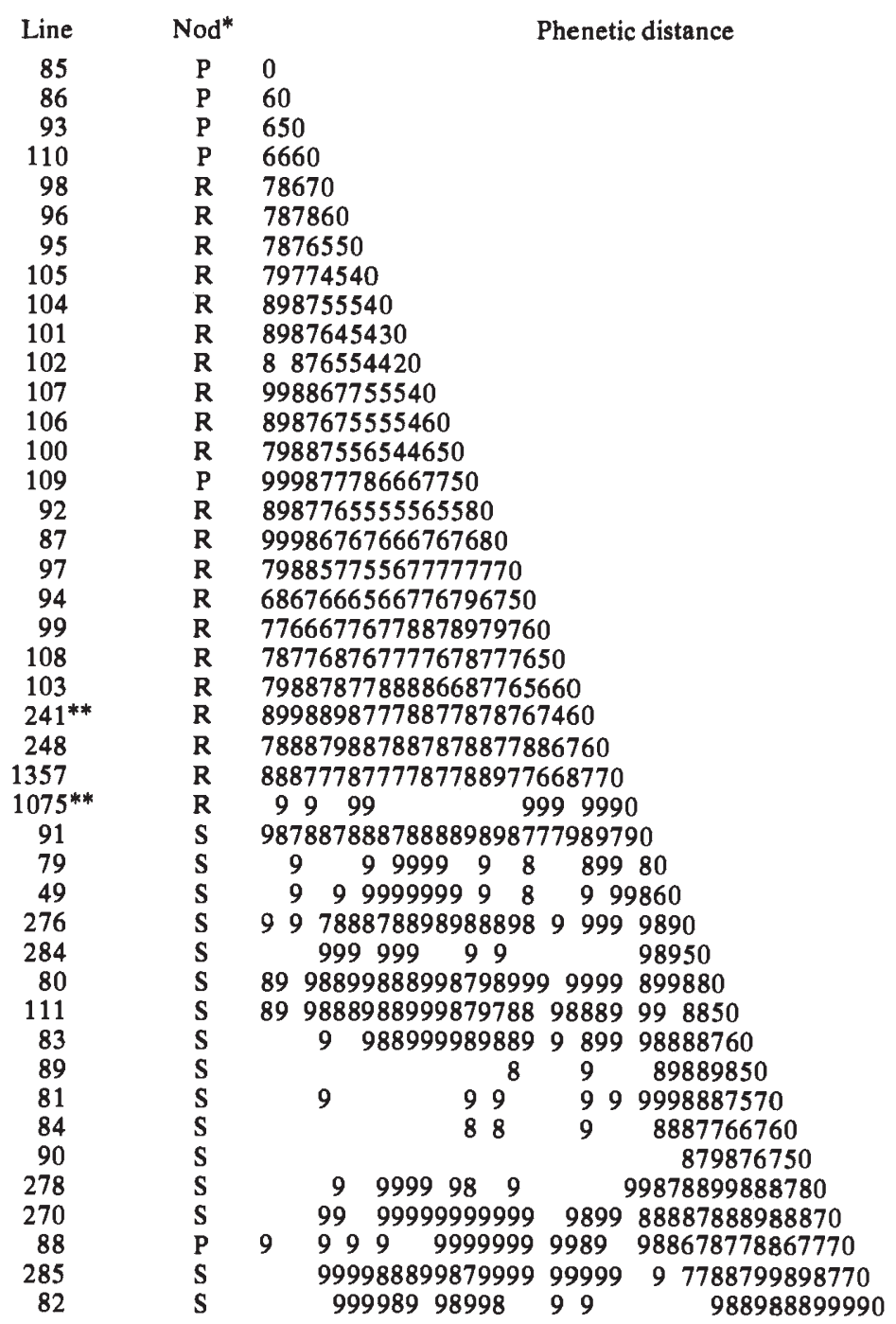

* Nodulation by European Rhizobium (as Table 1).

** Non-Afghan resistant lines included for comparison. 
nodulation or other root characteristics were used, but the pattern of relatedness corresponds closely with the pattern of resistance to European Rhizobium. The resistant Afghan lines form a close-knit group and are quite distinct from the susceptible lines, which are more diverse. The partially-resistant Afghan lines are similar to the resistant lines (except JI 88). The resistant JI 241 from Israel is very similar to the resistant Afghan lines, whereas the resistant JI 1075 from Turkey is quite distinct from all other lines in the analysis.

The resistant Afghan lines, and JI 241, all have coloured flowers, short, narrow pods with thin walls and no anthocyanin pigment, and non-wrinkled seeds with cream cotyledons and brown-marbled testas. In the majority of them, the foliage is light green and has no anthocyanin pigment, the flowers are small, and the seeds drum-shaped with a small hilum.

The partially resistant Afghan lines JI 85, 86, 93 and 110 form a related group, resembling the resistant lines in their small coloured flowers, small thin-walled pods, and marbled drum-shaped seeds with cream cotyledons, but differing in a number of respects, including darker foliage and more anthocyanin pigmentation of foliage, pods and leaf axils. Of the other two partially resistant lines, JI 109 is similar to the resistant lines, but JI 88 is quite different and resembles certain susceptible lines (table 2).

One very interesting characteristic of the Rhizobium-resistant lines that deserves special mention is their resistance to powdery mildew, Erysiphe polygoni. This resistance was expressed as complete absence of visible symptoms under field conditions in which susceptible lines were heavily infected (Matthews and Bayer, 1981). Out of 19 Rhizobium-resistant lines from Afghanistan, only 10 were Erysiphe-resistant, but this frequency is much higher than amongst Rhizobium-susceptible Afghan lines (1 out of 16) or amongst other $P$. sativum accessions in the Collection (17 out of 600 ).

The following Afghan lines were resistant to $E$. polygoni: JI 82, 92, $95,96,100,101,102,104,105,107$ and 108. The Turkish JI 1075 was also resistant.

\section{(ii) Comparison with a world-wide sample}

The Rhizobium-susceptible Afghan lines were very diverse, showing a range of variation typical of lines from elsewhere, whereas the resistant Afghan lines formed a distinct group (fig. 1). Four of the six partially resistant lines lie on the outer edge of this group. The Turkish JI 1075 had a high average distance from both susceptible and resistant groups. Seven non-Afghan susceptible lines were closely similar to the resistant group (mean distance less than 0.175); however, four of these did not have marbled seeds. The remaining three, from the Caucasus, Nepal and North India, were not distinguishable from the resistant lines by means of the characters studied, apart from their nodulation.

\section{Discussion}

\section{(i) The phenotype of resistant lines}

Resistance to nodulation by European Rhizobium is characteristic of, and appears to be almost confined to, a group of peas of distinctive appearance. Lie's "cv. Afghanistan" $(1971,1978)$ is a member of this 


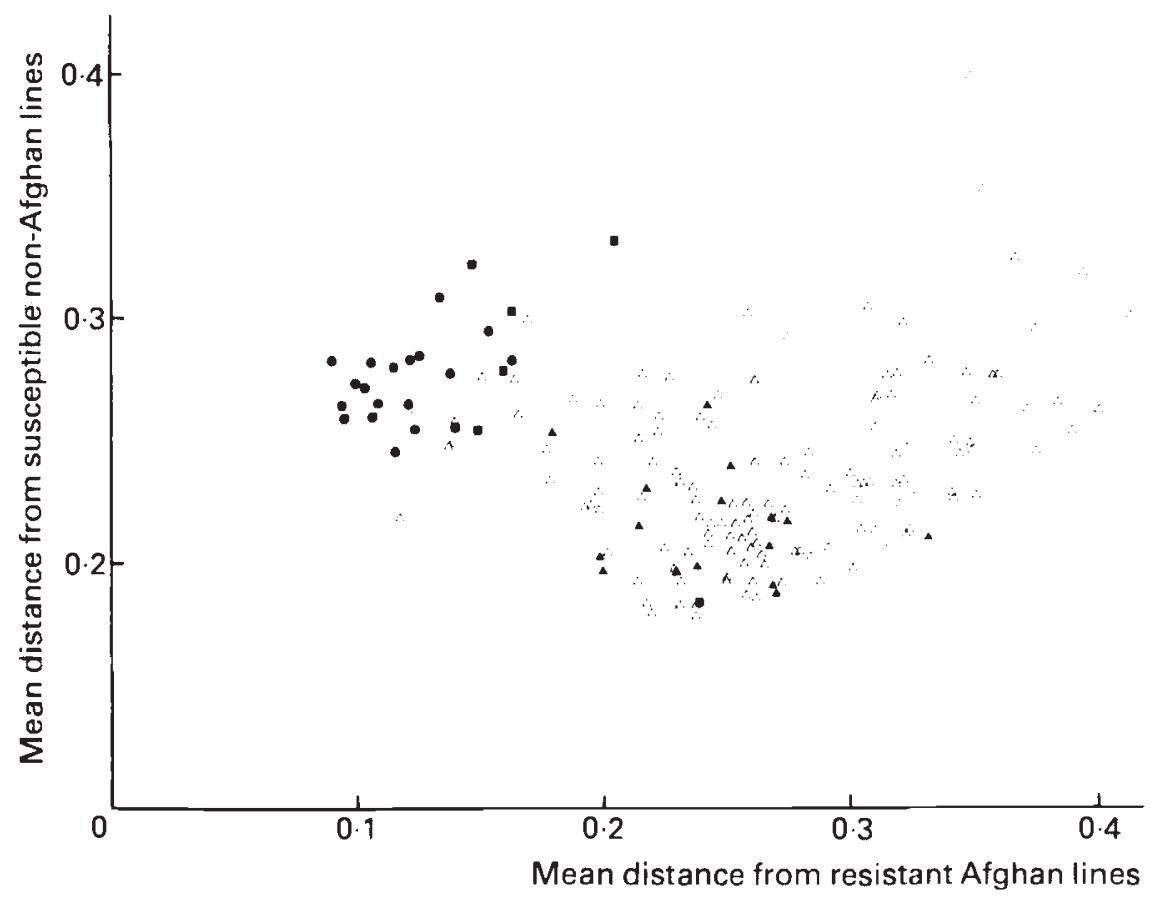

FIG. 1.-Mean phenetic distance of each pea line from the 19 Rhizobium-resistant Afghan lines and from the 130 susceptible lines from other countries. Self-comparisons omitted. $\boldsymbol{D}, \mathbf{\Delta}$ indicate resistant, partially resistant, and susceptible Afghan lines, respectively; $\triangle, O$ are susceptible and resistant non-Afghan lines.

group. These peas have been collected from a wide area in eastern Afghanistan, from Lal ( $300 \mathrm{~km} \mathrm{~W}$ of Kabul) and Ghazni (150 km SW) to Badakhshan $(300 \mathrm{~km} \mathrm{NE})$. They were mostly market samples and so, presumably, cultivated. Because of their small pods and small coloured flowers, which often have some "dirty" flavone pigmentation (unpublished observations), Govorov $(1928,1937)$ would place them in $P$. sativum subsp. asiaticum Gov., which includes similar cultivated forms ranging from N. Africa to Central Asia. The very similar JI 241 from Israel was, however, found growing wild, and the more recent classification of Ben-Ze'ev and Zohary (1973) would place this line, and probably all the resistant Afghan lines, in $P$. humile Boiss. and Noë, which they demonstrate to be a subspecies of $P$. sativum L.

The partially resistant lines JI 85, 86, 93, 109 and 110 are clearly similar in phenotype to the resistant lines, but they are rather further from the "typical" resistant form than are most of the resistant lines themselves. This may reflect some introgressive hybridization with other types, and the partial breakdown of resistance to European Rhizobium might, perhaps, result from the operation of the resistance gene in a "foreign" genetic background.

JI 1075 is resistant, and JI 88 is partially resistant, but these lines are totally different in general phenotype from the other resistant lines, and from each other. In the absence of genetic analysis, it is not known whether 
these represent independent sources of resistance or share a common genetic basis. There is some evidence that a similar mechanism might be involved, since all these lines are fully susceptible to Rhizobium strains carrying the plasmid pRL5JI (Young et al., 1982).

\section{(ii) The geographic distribution of resistance}

Lie (1978) examined numerous samples of soil bacteria from Europe, Africa, the Middle East, and one from Afghanistan, for their ability to nodulate cv. Afghanistan. All samples from Israel, Turkey and Afghanistan were successful, but none from elsewhere. It is striking that these are the same three countries that have yielded peas of cv. Afghanistan type. Wild peas of subsp. humile also grow in the intervening regions of Lebanon, Syria and Iran (Zohary and Hopf, 1973), and Govorov (1937) commented on the resistance to nodulation of some lines from Syria, while Lie (1978) identified one resistant line from Iran (as well as further lines from Israel and Afghanistan). It seems that resistant peas, wild or domesticated, may coexist with susceptible types throughout the region from Israel to Afghanistan, and it would be interesting to obtain information on the ecological distribution of these types.

On the basis of the fragmentary evidence, it is plausible that universal Rhizobium strains have a similar geographical range, but there is no information about the presence within this area of strains with limited host range. Unless such strains were present, the primary effect of the resistance gene would have no opportunity for expression.

\section{(iii) The absence of resistance from Europe}

The Middle East was an important centre for the domestication of peas (Ben Ze'ev and Zohary, 1973; Zohary and Hopf, 1973), and Afghanistan is a centre of diversity which may also have contributed to the cultivated forms (Govorov, 1928, 1937). The cultivated peas of Northern Europe were certainly not domesticated in situ, because no wild peas occur in the area. These peas are all susceptible to European Rhizobium leguminosarum, despite the fact that both susceptible and resistant forms occur in the regions of origin. There are two plausible explanations. One relates to the Rhizobium strains that nodulate peas in Northern Europe. These can also nodulate the wild Vicia and Lathyrus species of the area and it is probable that they are primarily adapted to these wild hosts. Indeed, it could be argued that the universal Rhizobium strains of the Middle East and Asia, able to nodulate all peas, are the "true" symbionts of peas; the European strains being symbionts of Lathyrus and Vicia that happen to nodulate some peas. Since the European strains cannot nodulate resistant peas, such peas would be poorly nodulated and would be selected against as pea cultivation spread north. However, universal Rhizobium strains occur throughout the area of original domestication, so there should have been no discrimination against resistant types during the development of cultivated peas in this area. The second explanation stems from the very narrow genetic base of the resistant peas examined in the present study. If resistance is largely restricted to a morphologically distinct type, it could be lost as a result of selection against other characteristics. These rather "wild" peas, 
which found favour in Afghanistan, may have been rejected in the Middle East as possessing little agronomic potential, so that the ancestors of modern European peas were, from the outset, able to nodulate with European Rhizobium.

Acknowledgements. - We thank Dr M. W. Johnson and Miss B. Mazdon for design and programming of the computer data base, Miss D. S. Rushbrook for assistance with recording, and Miss S. G. Dwyer of the NE Regional Plant Introduction Station, Geneva, NY for information on the origins of many accessions.

\section{REFERENCES}

BEN-ZE'EV, N., AND ZOHARY. D. 1973. Species relationships in the genus Pisum L. Israel J. Bot., 22, 73-91.

GovoroV, L. I. 1928. The peas of Afghanistan. Bull. Appl. Bot. Genet. Pl. Br., 19, 497-522. GOVOROV. L. I. 1937. Peas. In Cultivated Flora of the USSR, vol. 4, Moscow and Leningrad, pp. 231-336.

JOHNSON, M. W., SNOAD, B., AND DAVIES, D. R. 1971. A computer based record system for Pisum. Euphytica, 20, 126-130.

LIE, T. A. 1971. Symbiotic nitrogen fixation under stress conditions. Plant Soil, Special Volume, 117-127.

LIE, T. A. 1978. Symbiotic specialization in pea plants: the requirement of specific Rhizobium strains for peas from Afghanistan. Ann. Appl. Biol., 88, 462-465.

MATTHEWS, P., AND BAYER, O. 1981. Field resistance of peas to powdery mildew (Erysiphe polygoni). John Innes Ann. Rept. for 1980, 28-29.

MATTHEWS, P.. AND RUSHBROOK, D. 1981. John Innes Pisum Germplasm Collection. John Innes Ann. Rept. for 1980, 28.

SNEATH, P. H. A., AND SOKAL, R. R. 1973. Numerical Taxonomy. Freeman, San Francisco, $573 \mathrm{pp}$.

YOUNG. J. P. W., JOHNSTON, A. W. B., AND BREWIN, N. J. 1982. A search for peas (Pisum sativum $\mathrm{L}$.) showing strain specificity for symbiotic Rhizobium leguminosarum. Heredity, 48, 197-201.

ZOHARY, D., AND HOPF, M. 1973. Domestication of pulses in the old world. Science, 182, 887-894. 